\title{
Capsule Commentary on Min et al., Comparative Effectiveness of Insulin versus Combination Sulfonylurea and Insulin: a Cohort Study of Veterans with Type 2 Diabetes: How to Escalate Therapy for Patients who Fail Sulfonylureas
}

\author{
Ranee Chatterjee, MD, MPH and David Edelman, MD, MHS
}

Division of General Internal Medicine, Duke University, Durham, NC, USA.

$J$ Gen Intern Med 31(6):650

DOI: $10.1007 / \mathrm{s} 11606-016-3665-7$

(c) Society of General Internal Medicine 2016

$\mathrm{U}$ sing VA administrative data, Min et al. ${ }^{1}$ examined outcomes among diabetic patients who had failed sulfonylurea (SU) monotherapy and escalated therapy by transitioning to or adding insulin. With a median follow-up of 1.1 years, they found no differences between the groups for the outcomes of hypoglycemia, CKD, or cardiovascular events. Patients transitioned to insulin alone had slightly lower glycated hemoglobin compared to those transitioned to sulfonylurea and insulin (A1c reduced $0.2 \%$ and $0.4 \%$ at 24 and 36 months, respectively).

While metformin is the most common first-line therapy, many patients are treated with sulfonylureas, either because of intolerance to metformin or contraindications to metformin use. When a patient fails first-line therapy with any agent, there is no accepted guideline on escalating treatment. This study suggests that in patients failing monotherapy with sulfonylureas, clinicians should switch to insulin rather than add it to sulfonylureas, as this may lead to improvements in overall sugar control. Prospective data with longer followup would be needed to confirm this and to determine if this improvement in glycemia results in improvement in longterm outcomes; however, clinical trial data for this particular treatment comparison is unlikely, given that most current studies assume metformin to be the first-line therapy. ${ }^{2,3}$

Long-term comparative effectiveness trials are needed to assess outcomes in patients treated with sulfonylureas, metformin, newer diabetes medications, and their combinations. Sub-group analyses of these clinical trials or analyses of cohort data using advanced statistical methods may be needed to determine effects of specific treatment comparisons, including the one described in this study, on long-term outcomes; ${ }^{4}$ though these posthoc analyses are not as valid as well-designed comparative trials. Moreover, what is also needed to guide treatment decisions, in addition to high-quality evidence, is a tailoring of therapy with regards to patients' comorbidities and preferences. ${ }^{5}$

Corresponding Author: Ranee Chatterjee, MD, MPH; Division of General Internal Medicine, Duke University, 411 West Chapel Hill Street, Suite 500, Durham, NC 27701, USA (e-mail: ranee.chatterjee@duke.edu).

Compliance with Ethical Standards:

Conflict of Interest: The authors have no conflicts of interest with any of the material in this manuscript.

\section{REFERENCES}

1. Min JY GM, Hung AM, Grijalva CG, Greevy RA, Liu X, Elasy T, Roumie CL. Comparative effectiveness of insulin versus combination sulfonylurea and insulin: a cohort study of veterans with type 2 diabetes. J Gen Intern Med. doi:10.1007/s11606-016-3633-2.

2. Bennett WL, Maruthur NM, Singh S, Segal JB, Wilson LM, Chatterjee R, et al. Comparative effectiveness and safety of medications for type 2 diabetes: an update including new drugs and 2-drug combinations. Ann Intern Med. 2011;154(9):602-13.

3. Nathan DM, Buse JB, Kahn SE, Krause-Steinrauf H, Larkin ME, Staten $\mathbf{M}$, et al. Rationale and design of the glycemia reduction approaches in diabetes: a comparative effectiveness study (GRADE). Diabetes Care. 2013;36(8):2254-61.

4. Prentice JC, Conlin PR, Gellad WF, Edelman D, Lee TA, Pizer SD. Capitalizing on prescribing pattern variation to compare medications for type 2 diabetes. Value Health $\mathrm{J}$ Int Soc Pharmacoecon Outcomes Res. 2014; 17(8):854-62.

5. Inzucchi SE, Bergenstal RM, Buse JB, Diamant M, Ferrannini E, Nauck M, et al. Management of hyperglycemia in type 2 diabetes, 2015: a patientcentered approach: update to a position statement of the American Diabetes Association and the European Association for the Study of Diabetes. Diabetes Care. 2015;38(1): 140-9.

Published online March 18, 2016 